\title{
Os Cadernos de Sociomuseologia 1993-2012: da nova museologia à sociomuseologia.
}

Figurelli Gabriela ${ }^{5}$, Moutinho Mário ${ }^{6}$,

\begin{abstract}
Resumo
O presente artigo tem por objetivo analisar de forma global o trabalho desenvolvido entre 1993 e 2012 Pelos cadernos de Sociomuseologia (44 volumes publicados), a qual nasceu para servir a formação e a reflexão crítica que então era proposta no Curso de Pós graduação em Sociomuseologia Ao longo destes 19 anos os Cadernos tiveram sempre como centro da sua atividade a publicação de textos que de alguma forma pudessem contribuir para a reflexão e para a consolidação da Museologia enquanto Ciência Social mas tendo a Sociomuseologia como fio condutor. Esta opção resulta na verdade do contexto social e cultural no qual nasceram os primeiros programas de formação os quais tinham por objetivo acolher todos e todas as pessoas que já trabalhando em museus, tinham por referência a Ecomuseologia e/ou a nova museologia e naturalmente as preocupações relacionadas com a participação, a identidade, os processos dialógicos de atuar, os quais de uma forma ou outra se podiam relacionar com o conteúdo da Declaração da Mesa Redonda de Santiago de 1972 e da Declaração do Québec de 1984.
\end{abstract}

Palavras-chave: Sociomuseologia; Cadernos de Sociomuseologia

\begin{abstract}
This article aims to analyze globally the work between 1993 and 2012 by the Journal of Sociomuseology (44 volumes published), who was born to serve the education and the critical reflection that was proposed by the Post-Graduation program in Sociomuseology. During these 19 years the jornal have always been

\footnotetext{
${ }^{5}$ Universidade Federal de Pelotas, Brasil, gabrielafigurelli@hotmail.com

${ }^{6}$ Universidade Lusófona de Humanidades e Tecnologias, mcmoutin@gmail.com
} 
at the center of their activity the publication of texts that somehow could contribute to the reflection and consolidation of museology as social science but having the Sociomuseology as a guide. This option results in the truth of the social and cultural context in which they were born the first training programs which were designed to accommodate each and every person who already working in museums, had by reference to ecomuseology and / or new museology and of course concerns related to participation, identity, dialogic processes of acting, which in one way or another if they could relate to the content of the Declaration of Santiago Round Table 1972 and 1984 Quebec Declaration.

Keyword: Sociomuseology: Journal of Sociomuseology

O presente artigo tem por objetivo analisar de forma global o trabalho desenvolvido entre 1993 e 2012 por esta revista (44 volumes publicados), a qual nasceu para servir a formação e a reflexão crítica que então era proposta no Curso de Pós graduação em Sociomuseologia

Desde então, no Centro de Estudos de Sociomuseologia criado para enquadrar as atividade de ensino e de investigação, foi possível organizar os cursos de Pós graduação de 2 anos, que mais tarde estiveram na origem do Mestrado (2000) e do Doutoramento (2007)

No primeiro Semestre de 2013 fruto da necessidade de indexar internacionalmente a Revista, foi dado início a uma nova série na qual se passaram a respeitar todas as normas internacionais relativas às revistas científicas.

No âmbito desta reorganização, cuja necessidade há muito se fazia sentir, foram tomadas várias iniciativas visando o estabelecimento de uma política editorial melhor estruturada, tendo por objetivo reforçar a dimensão internacional e em simultâneo dotar o Departamento de Museologia de meios adequados para a disseminação da investigação científica 
realizada pelos nossos docentes e investigadores nos quais se incluem naturalmente os alunos de Mestrado e Doutoramento em Museologia.

Isso permitiu efetivamente submeter a nova revista para avaliação obtendo consequente a indexação, primeiro no Directory of Open Access Journals (DOAJ) e de seguida European Reference Index for the Humanities and the Social Sciences (ERIH PLUS) no início de 2014.

No quadro desta reorganização foi alargado e estruturado o Editorial \& Refree Board e o Advisory Board, reunindo para tal um vasto grupo de docentes e investigadores de universidades e Centros de Investigação nacionais (3) e de outros países (17).

Ao longo destes 19 anos os Cadernos tiveram sempre como centro da sua atividade a publicação de textos que de alguma forma pudessem contribuir para a reflexão e para a consolidação da Museologia enquanto Ciência Social mas tendo a Sociomuseologia como fio condutor. Esta opção resulta na verdade do contexto social e cultural no qual nasceram os primeiros programas de formação os quais tinham por objetivo acolher todos e todas as pessoas que já trabalhando em museus, tinham por referência a Ecomuseologia e/ou a nova museologia e naturalmente as preocupações relacionadas com a participação, a identidade, os processos dialógicos de atuar, os quais de uma forma ou outra se podiam relacionar com o conteúdo da Declaração da Mesa Redonda de Santiago de 1972 e da Declaração do Québec de 1984.

Foi de forma muito consciente, que Fernando Santos Neves escreveu na apresentação do primeiro volume dos Cadernos o seguinte texto: Efeito e causa da verdadeira 
revolução teórica e prática que, nos últimos tempos, vem tendo lugar na área das Ciências do Património e da Museologia, o Curso de Especialização em Museologia Social, quer pela sua qualidade substantiva quer pela quantidade das pessoas já formadas, deu um contributo decisivo para a consolidação entre nós, das novas vidências e vivências museológicas, que se procuraram sintetizar na designação terminológica $e$ epistemologicamente inovadora de Museologia Social ou SocioMuseologia. ${ }^{7}$

Levando em consideração que o crescimento e o fortalecimento de uma área do conhecimento passa, entre outros aspectos, pela comunicação científica é importante conhecer o perfil das ferramentas que desempenham este papel, uma vez que são elas que colaboram para a disseminação e a difusão do conhecimento que ocorre através da comunicação científica. A proposta deste texto é pois analisar os Cadernos de Sociomuseologia, ligada agora ao Centro de Estudos Interdisciplinares em Educação e Desenvolvimento, da Universidade Lusófona de Humanidades e Tecnologias de Lisboa .

De 1993 a 2012 foram publicados 44 volumes/números dos Cadernos de Sociomuseologia. Ao longo de 19 anos, diversos temas foram abordados e muitas reflexões foram propostas. A partir dos dados levantados e organizados, tornou-se possível desenhar um perfil da publicação, compreender suas linhas de atuação e sua abrangência no meio museológico, no que toca à divulgação acadêmica no âmbito da Museologia.

\footnotetext{
${ }^{7}$ Museologia Social e Sociomuseologia, Fernando Santos Neves, Cadernos de Sociomuseologia, n1-1993.

http://revistas.ulusofona.pt/index.php/cadernosociomuseologia/article/view/4 66
} 
A análise da publicação Cadernos de Sociomuseologia inicia com as suas coleções, as quais reúnem volumes que se assemelham de acordo com as características dos textos. A coleção 'Sociomuseology' éra destinada à divulgação, em língua inglesa, de idéias comuns ao contexto museológico ibero americano e conta com 4 números. A coleção 'Estudos PósGraduados' reúne dissertações de Mestrado, teses de Doutoramento e monografias de licenciatura e cursos de especialização relacionadas às principais temáticas abordadas pelos Cadernos de Sociomuseologia e totalizam 18 números. A 'Publicação destinada a um professor' é reservada à divulgação das ideias de docentes que contribuem para a reflexão e o desenvolvimento da teoria museológica e possuem estreita relação com os programas de Mestrado e Doutoramento em Museologia da ULHT. Somam 9 números. A publicação 'Diversos autores' agrupa textos de diferentes autores que abordam diferentes temáticas relacionadas à Museologia. São 10 números, dos quais 4 números são dedicados à publicação das atas de encontros e jornadas, um fato que reforça o apoio dos Cadernos à divulgação das ideias debatidas no meio museológico, em eventos. O nome 'Publicações diversas' é atribuído aos Cadernos voltados à documentação: tradução de documento, Manual do Utilizador para uma base de dados para acervos de museus de pequena dimensão, conjunto de documentos sobre museologia e patrimônio, produzidos pela UNESCO, ICOM, ICOMOS e o Conselho da Europa, totalizando 3 números. 


\section{Tipologia dos volumes}

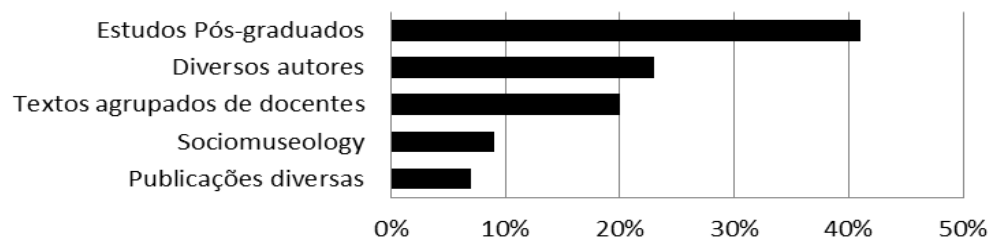

Fonte: Figurelli, Moutinho; 2014.

O gráfico evidencia que uma grande parcela das publicações, $41 \%$, está centrada nos estudos pós-graduados. Um dado que corrobora a intenção dos Cadernos de Sociomuseologia em divulgar os estudos académicos e assim incentivar a comunicação científica no âmbitos da Museologia, assim como o espaço que é aberto aos profissionais do meio em publicar seus escritos, através das edições que reúnem diversos autores e contabilizam 23\% dos Cadernos.

Este incentivo faz-se também através do livre acesso aos Cadernos. Desde o ano 1998 os Cadernos de Sociomuseologia estão disponíveis na internet, através do site que reúne todos os seus números/volumes e garante o acesso integral aos conteúdos das publicações. Ao assegurar um maior alcance à comunidade museológica, esta iniciativa traz benefícios para o meio ao estimular a divulgação de idéias, teorias, projetos e experiências e ao incentivar a produção de novas reflexões e partilhas. É assim um impacto positivo na produção acadêmica, uma importante referência aos estudantes de Museologia e um relevante veículo de comunicação científica.

No decorrer do período analisado, de 1993 a 2012, 230 textos foram publicados nos Cadernos de Sociomuseologia. De 
acordo com características comuns aos escritos foi possível definir categorias que agrupam estes artigos e demonstram os tipos de escritas mais frequentes nos Cadernos de Sociomuseologia. São elas: 'artigo conceitual' que reúne, sobretudo, idéias originais e contributos conceituais do próprio autor; 'artigo (revisão bibliográfica)', como o próprio nome especifíca, é o texto direcionado ao levantamento que cobre o assunto pesquisado; 'artigo (relato de experiência)' é o escrito que tem por base a narrativa de uma experiência vivida, palestras proferidas ou ainda anais de encontros, jornadas e seminários; 'artigo (projeto)' é a apresentação do planejamento de um projeto a ser implementado; 'tese de Doutoramento', 'dissertação de Mestrado', 'monografia de curso de Licenciatura e Especialização', corresponde aos trabalhos acadêmicos, em questão, na íntegra; 'investigação sistêmica' corresponde a um trabalho de pesquisa amplo e a 'tradução de documento' é o que o próprio nome especifica.

\section{Tipologia dos textos publicados}

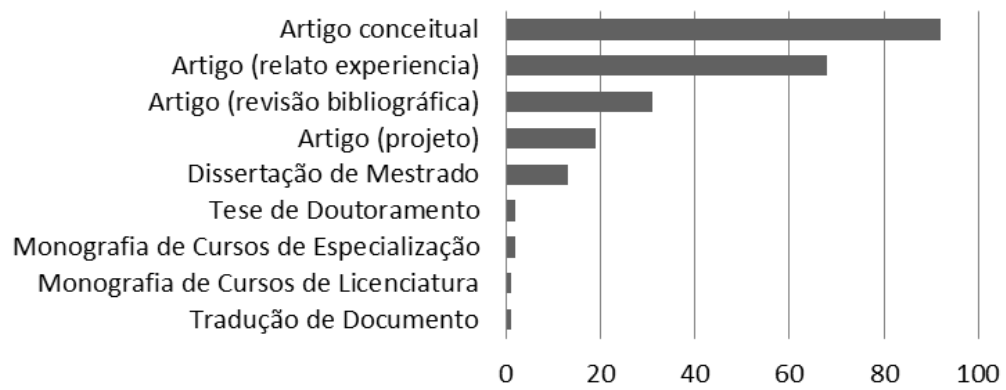

Fonte: Figurelli; Moutinho, 2014. 
Através desta análise, verificou-se uma predominância de estudos teóricos e estudos aplicados à Museologia. O gráfico permite observar que os artigos conceituais são os mais freqüentes - 92 textos - seguidos pelos artigos sobre relatos de experiência - 68 textos - e posteriormente os artigos sobre revisão bibliográfica - 31 textos. Dados que reforçam a natureza da publicação que tem como um dos seus principais objetivos o apoio à formação e à investigação, através da divulgação de ideias, problemáticas e desafios comuns ao meio museológico

O levantamento feito permitiu identificar, nesta primeira fase dos Cadernos de Sociomuseologia, 135 autores que tiveram seus textos publicados, entre artigos de autoria individual e coautoria. Dos 230 textos, apenas 16 são escritos de coautoria, número que demonstra que os Cadernos de Sociomuseologia caracterizam-se por reunir maioritariamente trabalhos singulares e raros textos com mais de um autor. Ainda sobre os autores, é possível verificar que as nacionalidades dos autores publicados são diversas. Contudo, predominam escritores oriundos de Portugal, Brasil, Espanha, Canadá, França, Holanda e México.

Os Cadernos são um conjunto de publicações que impulsiona a divulgação de projetos, investigações e experiências relacionadas ao patrimônio, às pessoas, aos espaços museológicos. Grande parte dos seus esforços procuram promover a reflexão e o debate atrelados à teoria museológica, aos conceitos e problemáticas que envolvem os profissionais ligados ao patrimônio e os estudantes universitários. Esforços centrados, sobretudo, numa Museologia social que tem a participação como uma das características mais marcantes e que verifica-se no próximo aspeto observado. Através da análise do conteúdo dos 230 artigos publicados fez-se um levantamento 
dos temas abordados e verificou-se quais as temáticas mais recorrentes nos Cadernos.

\section{Conteúdo dos textos}

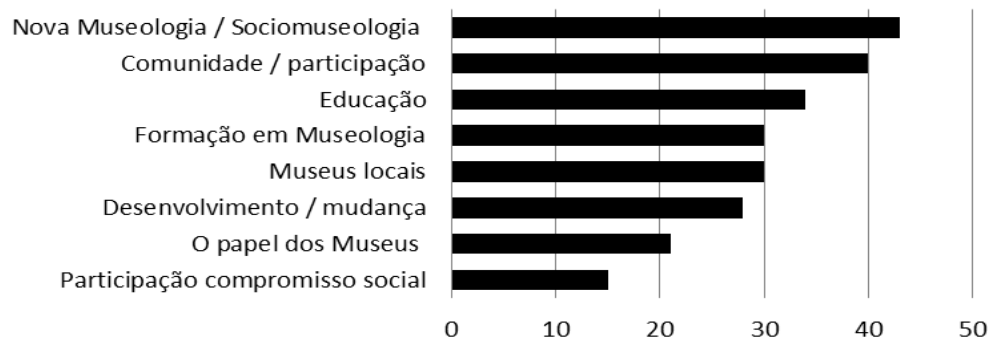

Fonte: Figurelli; Moutinho; 2014

A Nova Museologia, juntamente com a Sociomuseologia e toda sua envolvente, seus desafios, seus compromissos, suas propostas são temas centrais de $\mathbf{4 3}$ artigos publicados pelos Cadernos de Sociomuseologia.

A comunidade e sua atuação junto aos projetos e espaços museológicos, a participação das pessoas como diferencial qualitativo das iniciativas relacionadas ao patrimônio foi um tema referenciado em $\mathbf{4 0}$ artigos.

A Educação no âmbito da Museologia juntamente com a Educação Não-Formal, a ação educativa, o recurso educativo e a aprendizagem em museus são temas recorrentes em 34 artigos que abordam o caráter educativo dos museus, o potencial para a Educação inerente ao patrimônio e demais desafios comuns a este contexto.

Os museus locais, os ecomuseus os museus de território, os museus comunitários e todos os projetos que se assemelham com estas propostas são tema de $\mathbf{3 0}$ artigos que apresentam, 
destacam, refletem e discutem esta tipologia de museus que muito diz sobre a participação.

A formação profissional no domínio da Museologia, tanto no contexto universitário como conectada ao 'International Committee for the Training of Personnel' (ICTOP) o comitê do ICOM que busca promover a formação e o desenvolvimento profissional é tema de $\mathbf{3 0}$ artigos publicados pelos Cadernos.

Textos que abordam o desenvolvimento tanto na esfera local, como urbana, comunitária, social e territorial e reforçam as possibilidades do patrimônio enquanto contributo, foram detectados $\mathbf{2 8}$ artigos.

Sobre o papel do museu e sua identidade, as mudanças atreladas ao seu posicionamento frente à sociedade e a própria mudança de paradigma vivida nos museus, identificou-se 21 artigos referentes ao tema em questão.

A comunicação no âmbito da Museologia, envolvendo o público e o patrimônio é um assunto presente em $\mathbf{2 1}$ artigos.

O conjunto de documentos referenciais para refletir sobre a ação museal a partir da ótica da participação e do compromisso social - Declaração de Santiago do Chile 1972 ICOM-UNESCO, Declaração de Quebec 1984 MINOM-ICOM, Declaração de Caracas 1992 ICOM-UNESCO, Declaração de Lisboa 1994 ICOM-UNESCO - é tema de 15 artigos. Os indicadores apresentados dão assim conta do percurso seguido pelos Cadernos de Sociomuseologia ao longo destes 19 anos. Tratou-se na verdade de uma publicação que se foi adaptando às necessidades da formação prestada aos mestrandos e doutorandos, que na sua maioria eram já profissionais atuando no quadro da museologia social. Para estes se foi construindo uma bibliografia que de algum modo correspondia às 
interrogações que todos, docentes e discentes, se colocavam como profissionais ou como cidadãos, em busca de resposta para as muitas inquietações, dúvidas e certezas que carreavam.

A nova serie dos Cadernos de Sociomuseologia, publicada a partir do no 45-2013, não enjeita o trabalho realizado. Apenas se adaptou aos tempos que correm, que para bem da qualidade, obrigam à adoção de formas de editar mais exigentes compatíveis com a sua indexação internacional. 